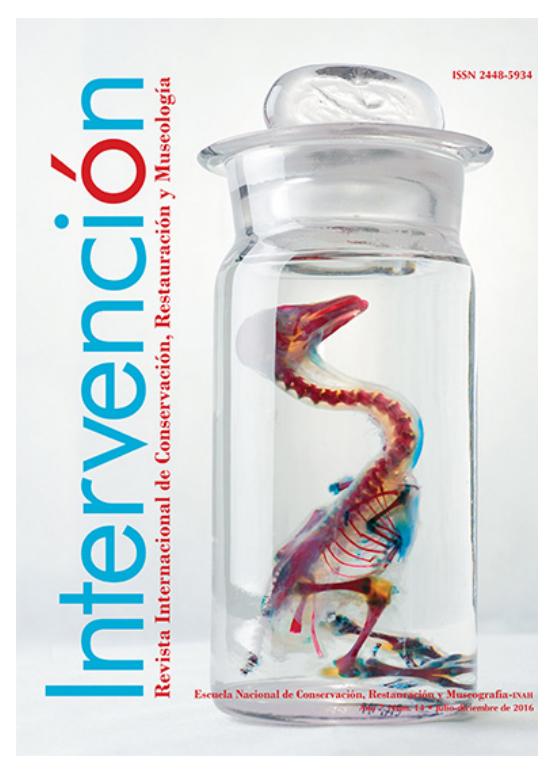

\section{Revista Internacional de Conservación, Restauración y Museología, 7(14), julio-diciembre 2016}

\author{
Isabel Medina-González (Editora) \\ Escuela Nacional de Conservación, Restauración y \\ Museografía, México. 2016
}

Páginas: 322

Idioma: Español/Inglés

ISSN 2448-5934
Reseña del último número de la revista Intervención, publicada por la Escuela Nacional de Conservación, Restauración y Museografía, adscrita al Instituto Nacional de Antropología e Historia, México. Se presenta una valoración crítica del contenido y se enfatiza la pertinencia de la publicación como una vía abierta de diálogo entre profesionales.

Ocho años se dicen fácil, pero sin duda no lo es si dicha cantidad se piensa con relación a los espacios de producción y difusión académica que en el transcurso de ese periodo han surgido y cesado de publicarse, entre glorias y penas. Este nuevo número de Intervención, el 14, es también el primero en el que la revista posee el rango de publicación arbitrada con competencia internacional.

Bajo la edición de Isabel Medina y coordinado en esta ocasión por Dafne Juliana Díaz de la Vega Núñez, el volumen tiene como hilo conductor la transdisciplina. Los seis artículos incluidos abordan este aspecto: desde la importancia de la colaboración interdisciplinar en términos de metodología, investigación experimental e interpretación de datos, hasta en la necesidad de ampliar el sentido mismo del término, con la finalidad de consolidar cuerpos conceptuales, criterios, marcos de operación y estructuras de gestión.

El artículo de Astrid Esquivel y Laura Filloy Nadal, "Evaluación del proceso de carbonatación de nanocales aplicadas a pinturas murales prehispánicas de origen maya", y el de Claudia García Solís, Demetrio Mendoza Anaya y Patricia Quintana Owen, "La escultura arquitectónica modelada en estuco de Calakmul, Campeche, México: la transformación material en el proceso tecnológico", presentan los resultados de la investigación aplicada. Si bien ambos documentos poseen un marcado perfil técnico, el primero se detiene en el nivel experimental, mientras que el segundo hace énfasis en la selección del enfoque de análisis para la interpretación de datos. Los reportes revisten interés no sólo por la utilidad que la información técnica sobre los nanocales pueda tener para conservadores y restauradores, o por la descripción puntual respecto a cómo el análisis matérico puede resultar una fuente de información sobre el contexto histórico, arquitectónico y cultural maya; sino porque tanto en uno y otro, la descripción de cómo fue planteado el muestreo, la prueba y el modelo de interpretación de resultados, deja ver al lector lo necesario de que la colaboración disciplinar sea parte fundamental en el trabajo institucional.

Lamentablemente, esto último es una tarea pendiente. Tal cual puede leerse entre líneas en la semblanza sobre la Red de Ciencias Aplicadas a la Investigación y Conservación del Patrimonio Cultural (Red-caicpc), dichas sinergias han sido resultado del esfuerzo conjunto de individuos particulares, quienes desde sus oficinas, museos, aulas y centros de investigación en México, han buscado tender lazos profesionales y establecer mecanismos de investigación. La existencia de la red demanda el despliegue de una política institucional en concreto, no sujeta a caprichos administrativos y a programas de contentillo, que permitiera estructurar acciones integrales para la conservación, investigación y difusión del patrimonio, la producción académica y avance metodológico.

El número también presenta tres textos que ponen en 
entredicho la idea misma de lo "disciplinar", la construcción de conocimiento, su sistematización y las categorías epistemológicas que sirven de marcos de referencia e interpretación.

El primero de ellos "Perspectivas y reflexiones sobre la conservación preventiva: la instrumentación del enfoque de sistemas", escrito por María de Lourdes Graciela Gallardo Parrodi y Ana Laura Peniche Montfort, propone que la conservación no debe ser enfocada como un proceso aislado sino como parte de un conjunto mayor de acciones técnicas, de intervención y de gestión. Con claras referencias a la metodología utilizada en la elaboración y evaluación de proyectos culturales (sobre todo, del contexto español y británico), el artículo resalta por su claridad expositiva, aunque, a juicio personal, no resulta novedoso. En todo caso, la novedad estriba en el no muy grato hecho de caer en cuenta de que lo que debería ser protocolo en la práctica profesional, en la realidad no lo es.

Por su parte, el recuento que presenta Miguel Ángel Mesinas en su reporte titulado "El derecho del patrimonio cultural. Análisis desde la perspectiva de los derechos humanos y su aplicación por el Instituto Nacional de Antropología e Historia (inah), México" es de gran pertinencia en un momento en el cual se discute la conformación de la Ley General de Cultura. Pese a su brevedad, ofrece un buen marco para observar la dificultades para hacer operativos conceptos legales internacionales en contextos particulares, así como para reflexionar desde dónde se construyen los criterios normativos, las discrepancias en la interpretación de los mismos y la falta de vinculación existente entre el discurso legal como cuerpo jurídico y su realidad institucional.

Un acercamiento a la idea de interdisciplina como "diálogo de saberes" en constante flujo es el que brinda María Guillermina Fressoli en su informe sobre el Museo Móvil. Éste es una iniciativa del Museo de los Asentamientos, localizado en Federación, Entre Ríos, Argentina. Si bien la autora analiza una propuesta museal y museográfica particular - la manera en cómo el museo ha buscado construir una relación con los habitantes, quienes asumen su pasado reciente como un evento "traumático", en tanto se viven como desplazados y desterritorializados-, el estudio de caso pone sobre la mesa puntos críticos por encima del contexto local al que se haya referido. Dos de ellos son capitales. Uno es el atributo dado al museo como dispositivo de la memoria: en qué medida la institución está dispuesta a cuestionar la narrativa que de la misma construye, y si es capaz de ver su papel dentro de los procesos de gentrificación y resistencia cotidiana. Si bien otros investigadores han trabajado el tema de la memoria y el museo, lo interesante del artículo es el elemento de incertidumbre que introduce con respecto a si e "la conciliación" con el pasad es un elemento de cohesión colectiva o de contención social. Lo segundo es el aparente repliego de la voz de autoridad del museo para dar espacio a los otros como sujetos con igual rango. La pregunta, por supuesto, es qué sucederá una vez que esa construcción de conocimiento conjunto entre dentro de las estructuras institucionalizadas del museo. Pese a que la lectura del texto puede resultar un tanto pesada por el exceso de notas a pie, es uno de los más sugerentes de la revista.

La calidad de este número 14 pierde piso con el texto de Naudy Trujillo, "Los museos veterinarios: puntos de encuentro entre la historia y la ciencia". La premisa inicial promete, pero el desarrollo es pobre y se reduce a referir una serie de datos e información sobre la historia de los museos en general. Es una lástima pues si bien en Latinoamérica hay investigación sobre museos de ciencia, son pocos los buenos textos en las que se atienda a su especificidad discursiva, tanto conceptual como museográfica.

La revista incluye también una reseña del libro de Jéssica Ramírez Puente, Los carmelitas descalzos en la Nueva España. Del activismo, a cargo de Leticia Pérez, que cumple con su objetivo de presentar y poner en contexto el libro en cuestión.

Sin duda, Intervención es uno de los proyectos editoriales más consistentes. Este número de nueva cuenta refrenda los que son sus mejores rasgos en tanto proyecto: rigor en la selección de textos, articulación de los contenidos, amplitud disciplinar -no es la "revista de los conservadores" o "la revista de los museólogos"-, cuidado de la edición y el manejo de un lenguaje claro que la hace accesible a una audiencia de lectores más amplia de lo que podría pensarse. Pero, considero que la revista sigue debiendo el que arriesgue a ser un foro de debate mucho más activo. Estoy segura que conforme el proyecto continúe, habrá de conseguirlo. 